\title{
ANALISIS KELAYAKAN FINANSIAL USAHA BUDI DAYA IKAN LELE DUMBO (Clarias gariepinus) DI KOLAM TERPAL DAN KOLAM PERMANEN PADA UD. REPUBLIK LELE KABUPATEN KEDIRI
}

Business Financial Feasibility Analysis of Dumbo Catfish Cultivation (Clarias gariepinus) in Swimming Pool and Permanent Pond at UD. Lele Republic of Kediri Regency

\author{
Zainal Abidin, A.A.P. Agung Suryawan Wiranatha*, Sri Mulyani \\ PS Teknologi Industri Pertanian, Fakultas Teknologi Pertanian, Universitas Udayana, Kampus Bukit \\ Jimbaran, Badung, Kode pos : 80361; Telp/Fax : (0361) 701801.
}

Diterima 14 Nopember 2018 / Disetujui 07 Januari 2019

\begin{abstract}
The purpose of the study was to analyze the financial feasibility of Clarias gareipinus cultivation in tarpaulin ponds and permanent ponds UD. Republik Lele in Kediri Regency, East Java. The method used is the analysis of profit-loss calculations using the Net Present Value (NPV), Internal Rate of Return (IRR), Net B / C Ratio, Pay Back Period (PBP), and Break Event Point (BEP). The results of the study show that. The results showed that the stages of catfish cultivation included the process of spawning, catfish egg hatching, seed grading, and the augmentation process. Spread density in permanent ponds of 500 seedlings / $\mathrm{m} 2$, tarpaulin ponds of 450 seedlings $/ \mathrm{m} 2$ as a whole the business of profitable catfish cultivation, with an average net pool profit of Rp. 23,918,347 / cycle / pond and tarpaulin pool Rp. 19,005,054 / pool / cycle. Based on the analysis of financial feasibility of permanent ponds and tarpaulins in a row generate (NPV) Rp. Rp 5,975,446,295 and Rp 1,645,894,923 (IRR) of $17.62 \%$ and $10.57 \%$, (PBP) for 3 years and 3 years 9 months, Net B / C Ratio of 1.20 and 1.19, and (BEP) in the amount of Rp. 11,082,314,678 and Rp. 8,238,792,702/year. This business is feasible to be developed.
\end{abstract}

Keywords: financial feasibility, tarpaulin pool, permanent pond, catfish

\section{ABSTRAK}

Tujuan dari penelitian adalah untuk menganalisa kelayakan finansial budi daya ikan lele di kolam terpal dan kolam permanen UD. Republik Lele di Kabupaten Kediri Jawa Timur. Metode yang digunakan adalah analisis perhitungan laba-rugi menggunakan Net Present Value (NPV), Internal Rate of Return (IRR), Net B/C Ratio, Pay Back Period (PBP), dan Break Event Point (BEP). Hasil penelitian menunjukkan bahwa. Hasil penelitian menunjukkan bahwa tahapan budi daya lele meliputi proses pemijahan, penetasan telur lele, grading bibit, dan proses pembesaran. Kepadatan tebar pada kolam permanen 500 ekor bibit $/ \mathrm{m}^{2}$, kolam terpal 450 ekor bibit $/ \mathrm{m}^{2}$ secara keseluruhan usaha budi daya ikan lele menguntungkan, dengan rata - rata keuntungan bersih kolam permanen Rp 23.918.347/siklus/kolam dan kolam terpal $\mathrm{Rp}$ 19.005.054/kolam/siklus. Berdasarkan analisis kelayakan finansial kolam permanen dan terpal secara berturut-turut menghasilkan (NPV) Rp. Rp 5.975.446.295 dan Rp 1.645.894.923, (IRR) sebesar 17,62\% dan 10,57\%, (PBP) selama 3 tahun dan 3 tahun 9 bulan, Net B/C Ratio sebesar 1,20 dan 1,19, serta (BEP) sebesar Rp 11.082.314.678 dan Rp 8.238.792.702/tahun. Usaha

*Korespondensi Penulis:

Email : agung_suryawan@unud.ac.id 
tersebut layak untuk dikembangkan.

Kata Kunci : kelayakan finansial, kolam terpal, kolam permanen, ikan lele

\section{PENDAHULUAN}

Lele Dumbo (Clarias gariepinus) merupakan salah satu jenis ikan air tawar yang telah dibudidayakan secara komersial oleh masyarakat di Indonesia terutama di provinsi Jawa Timur. Kebanyakan kabupaten di Jawa Timur umumnya membudidayakan ikan lele Dumbo pada kolam. Pada provinsi Jawa Timur produksi ikan lele Dumbo pada budi daya kolam tahun 2010 hingga tahun 2015 mengalami peningkatan sebesar $27,21 \%$, yaitu 242.811 ton hingga 679.379 ton, dan hingga triwulan III tahun 2015 sebesar 396.539 ton (Ditjen Perikanan Budi Daya, 2015). sehingga budi daya ikan lele dumbo merupakan usaha yang menjanjikan. Dalam usaha budi daya ikan lele terdapat dua kegiatan besar yang harus diperhatikan yaitu usaha pembenihan dan pembesaran. Kegiatan pembenihan merupakan kegiatan pendahuluan di dalam budi daya. Tanpa kegiatan pembenihan maka kegiatan selanjutnya seperti pendederan dan pembesaran tidak akan terlaksana (Setiawan, 2006).

Salah satu usaha yang bergerak dalam pembudidayaan lele di Kabupaten Kediri adalah UD. Republik Lele. Usaha ini mulai melakukan pembudidayaan lele sejak tahun 1980. Pada tahun 1980 - 1982 jenis lele yang dibudidayakan yaitu lele lokal (Clarias batracus) dilakukan secara tradisional, pada tahun 1984 - 1986 jenis yang dikembangkan adalah lele dumbo menggunakan teknik pemijahan injeksi hipofisa lalu di stripping, tahun 1987 sampai sekarang pemijahan dilakukan dengan teknik kawin alami.

Pada umumnya petani ikan yang memiliki skala produksi besar akan lebih memilih pembudidayaan menggunakan kolam permanen, pembudidayaan menggunakan kolam permanen ini dilakukan karena kolam permanen memiliki keunggulan masa pakai yaitu 15 sampai 20 tahun, memiliki tingkat kebocoran kolam yang kecil, lebih mudah dalam pengontrolan air, tingkat kematian ikan lebih rendah, suhu kolam beton cenderung lebih stabil dibandingkan dengan kolam terpal ini sangat penting untuk menjaga agar ikan tidak mudah mengalami stress. Terpal merupakan bahan plastik dan memiliki sifat kedap air, sifat ini yang membuatnya berguna sebagai lapisan penahan air di kolam. Kolam terpal pada umumnya sudah biasa digunakan oleh peternak ikan hias, tetapi pada peternak ikan konsumsi masih jarang digunakan. Keunggulan penggunaan kolam dari terpal antara lain kolam terpal mudah dibuat, suhu kolam lebih stabil dibandingkan kolam tanah. Selain biaya yang dikeluarkan menjadi lebih kecil di bandingkan menggunakan kolam permanen.

Beberapa penelitian mengenai perhitungan kelayakan finansial yaitu kelayakan finansial hasil penelitian Bahri (2014) mengenai biji kakao kering, yaitu Net Present Value sebesar 29.698.765.000, Internal Rate of Return 23\%, Payback Period 6 tahun 7 bulan dan Net B/C rasio 1,58. Hasil penelitian Dewi et al. (2017), analisis kelayakan finansial minuman bubuk bawang berlian yaitu Net Present Value (NPV) sebesar Rp. 391.505.116, Internal Rate of Return (IRR) 30\%, Payback Period (PP) selama 1 tahun 4 bulan, dan Net B / C Rasio 2,14 .

Hingga saat ini masih belum ada penelitian mengenai analisis keuangan usaha budi daya ikan lele menggunakan kolam terpal dan kolam permanen. Menghitung keberhasilan kegiatan usaha tidak semata dilihat dari peningkatan produksi. Keberhasilan usaha perlu diketahui dengan menganalisis kelayakan finansial untuk 
mengetahui apakah usaha tersebut menguntungkan atau tidak (Tyas et al., 2015). Menurut Soekartawi (1991) analisis finansial dilakukan dengan menggunakan data harga yang sebenarnya ditemukan di lapangan, sehingga dapat segera dilakukan penyesuaian bila proyek tersebut berlangsung menyimpang dari rencana semula. Berdasarkan permasalahan di atas penelitian ini bertujuan menentukan kelayakan finansial usaha budi daya ikan lele dumbo (Clarias gariepinus) di kolam terpal dan kolam permanen Pada UD. Republik Lele Kabupaten Kediri ”.

\section{METODE PENELITIAN}

Penelitian ini dilakukan pada UD. Republik Lele, Kabupaten Jawa Timur. Waktu penelitian dilakukan dari bulan Juni Juli 2018. Penelitian dilakukan dengan tahapan yang dimulai dari identifikasi masalah dan tujuan, studi pustaka, pengumpulan data (data primer dan data sekunder), analisis data. Tahapan penelitian yang disebutkan disajikan pada Gambar 1 .

Pengumpulan data yang dibutuhkan dalam penelitian ini adalah data primer dan data sekunder. Data primer yang digunakan dalam penelitian ini berupa harga jual, komponen biaya investasi, biaya tetap dan biaya tidak tetap yang diperoleh dari hasil wawancara, diskusi dan pengamatan lapangan. Data sekunder yang digunakan pada penelitian ini adalah data potensi dan keadaan umum wilayah, data pembudidaya ikan lele di Kabupaten Kediri, data penjualan ikan lele di Kabupaten Kediri, dan data produksi ikan lele di Kabupaten Kediri, Data tersebut diperoleh dari dinas Kelautan dan Perikanan Provinsi Jawa Timur, Pusat Data Statistik Kabupaten Kediri.

Analisis data yang dilakukan dalam penelitian ini menggunakan analisis perhitungan laba-rugi Net Present Value $(N P V)$, Internal Rate of Return (IRR), Net
B/C Ratio, Pay Back Period (PBP), dan Break Event Point (BEP) pada program Microsoft Excel.

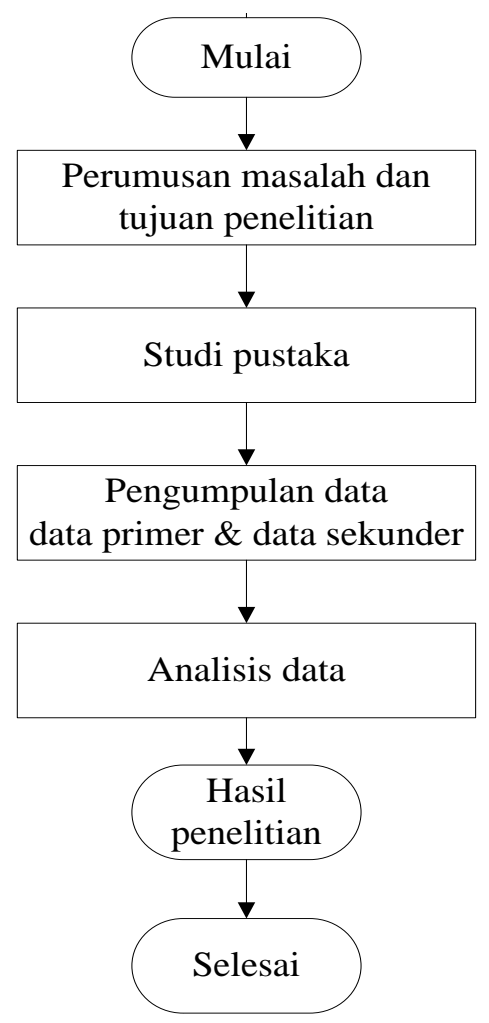

Gambar 1. Skema Tahapan Penelitian

\section{HASIL DAN PEMBAHASAN}

\section{Gambaran Umum Perusahaan}

UD. Republik Lele merupakan salah satu usaha budi daya ikan lele yang sudah berdiri sejak tahun 1985. Usaha ini didirikan oleh H. M. Akas Alamuddin yang berlokasi di J1. Asparaga no. 21 Tegalsari Tulungrejo Kecamatan Pare Kabupaten Kediri. UD. Republik Lele merupakan usaha skala menengah yang bergerak di bidang pembudidayaan ikan air tawar, khususnya budi daya ikan lele.

Pada UD. Republik Lele terdapat dua jenis kolam yaitu kolam terpal dan kolam permanen yang terbagi menjadi 853 kolam terpal dengan ukuran luas kolam rata-rata 45 $\mathrm{m}^{2}$ panjang 9 meter dan lebar 5 meter, serta 560 kolam permanen dengan ukuran luas kolam rata-rata $50 \mathrm{~m}^{2}$ panjang 10 meter dan 
lebar 5 meter maka total kolam keseluruhan adalah 1413 kolam, berdasarkan perhitungan kebutuhan biaya yang diperlukan untuk pembangunan 1413 kolam terpal dan kolam permanen serta pembelian lahan adalah sebesar Rp 18.687.600.000, kebutuhan ratarata biaya operasional untuk kolam permanen dan terpal/Ha selama satu tahun berturutturut adalah sebesar Rp. 22.294.878.388 dan Rp 13.452.807.453. Maka peneliti mengasumsikan bahwa pemilik UD.
Republik Lele membutuhkan modal sebesar Rp 100.000.000.000 dimana modal tersebut terbagi menjadi dua yaitu modal pribadi sebesar Rp 50.000.000.000 dan modal pinjaman bank sebesar Rp 50.000.000.000 . Perincian komponen biaya investasi kolam permanen dan kolam terpal dapat dilihat pada Tabel 1, perincian lokasi dan jenis kolam pada UD. Republik Lele dapat dilihat pada Tabel 2.

Tabel 1. Biaya investasi usaha budi daya ikan lele

Biaya Investasi Usaha Budi Daya Ikan Lele

\begin{tabular}{|c|c|c|c|c|c|c|c|c|c|c|}
\hline No & Jenis Biaya & Jumlah & Satuan & \multicolumn{2}{|c|}{$\begin{array}{c}\text { Harga Per } \\
\text { Satuan }\end{array}$} & & Nilai & $\begin{array}{c}\text { Umur } \\
\text { Ekonomis(thn) }\end{array}$ & \multicolumn{2}{|c|}{ Penyusutan } \\
\hline 1 & $\begin{array}{l}\text { Kolam } \\
\text { permanen }\end{array}$ & 560 & kolam & $\mathrm{Rp}$ & 12.389 .821 & $\mathrm{Rp}$ & 6.938 .300 .000 & 15 & $\mathrm{Rp}$ & 462.553 .333 \\
\hline 2 & Kolam Terpal & 853 & kolam & $\mathrm{Rp}$ & 10.092 .614 & $\mathrm{Rp}$ & 8.609 .000 .000 & 7.5 & \multicolumn{2}{|c|}{ Rp1.147.866.667 } \\
\hline 3 & Mesin Selip & 5 & unit & $\mathrm{Rp}$ & 5.000 .000 & $\mathrm{Rp}$ & 25.000 .000 & 5 & $\mathrm{Rp}$ & 5.000 .000 \\
\hline 4 & Pompa Air & 253 & unit & $\mathrm{Rp}$ & 1.450 .000 & $\mathrm{Rp}$ & 366.850 .000 & 5 & $\mathrm{Rp}$ & 73.370 .000 \\
\hline 5 & Sumur & 96 & unit & $\mathrm{Rp}$ & 10.000 .000 & $\mathrm{Rp}$ & 960.000 .000 & 15 & $\mathrm{Rp}$ & 64.000 .000 \\
\hline & $\begin{array}{c}\text { Alat } \\
\text { Administrasi }\end{array}$ & Jumlah & Satuan & \multicolumn{2}{|c|}{$\begin{array}{c}\text { Harga Per } \\
\text { Satuan }\end{array}$} & & Nilai & $\begin{array}{c}\text { Umur } \\
\text { Ekonomis(thn) }\end{array}$ & \multicolumn{2}{|c|}{ Penyusutan } \\
\hline 1 & Komputer & 1 & Unit & $\mathrm{Rp}$ & 4.000 .000 & $\mathrm{Rp}$ & 4.000 .000 & 5 & $\mathrm{Rp}$ & 800.000 \\
\hline 2 & Meja & 1 & Unit & $\mathrm{Rp}$ & 750.000 & $\mathrm{Rp}$ & 750.000 & 5 & $\mathrm{Rp}$ & 150.000 \\
\hline 3 & Kursi & 1 & Unit & $\mathrm{Rp}$ & 200.000 & $\mathrm{Rp}$ & 200.000 & 5 & $\mathrm{Rp}$ & 40.000 \\
\hline 4 & Rak & 1 & Unit & $\mathrm{Rp}$ & 700.000 & $\mathrm{Rp}$ & 700.000 & 5 & $\mathrm{Rp}$ & 140.000 \\
\hline 5 & $\begin{array}{l}\text { Ruang Kantor } \\
\text { Jumlah }\end{array}$ & 1 & Ruangan & $\mathrm{Rp}$ & 13.500 .000 & $\begin{array}{l}\mathrm{Rp} \\
\mathbf{R p}\end{array}$ & $\begin{array}{c}13.500 .000 \\
\mathbf{1 9 . 1 5 0 . 0 0 0}\end{array}$ & 15 & $\begin{array}{l}\mathrm{Rp} \\
\mathbf{R p}\end{array}$ & $\begin{array}{r}900.000 \\
\mathbf{2 . 0 3 0 . 0 0 0}\end{array}$ \\
\hline
\end{tabular}

Tabel 2. Lokasi dan jumlah kolam UD. Republik Lele

\begin{tabular}{llccc}
\hline \multirow{2}{*}{ No } & \multicolumn{2}{c}{ Lokasi } & Luas Lahan (Ha) & \multicolumn{2}{c}{ Jenis kolam dan jumlah } \\
& & 0,70 & & 132 \\
\hline 1 & Desa Beringin & 0,80 & & 149 \\
2 & Desa Nganten & 1,50 & 170 & 279 \\
3 & Desa Tulungrejo 1 & 1,2 & 142 & \\
4 & Desa Tulungrejo 2 & 1,0 & 100 & \\
5 & Desa Tulungrejo 3 & 0,7 & 85 & \\
6 & Desa Tulungrejo 4 & 0,6 & 170 & \\
7 & Desa Tulungrejo 5 & 1,2 & 114 & \\
8 & Desa Gedangsewu & 0,8 & 72 & \\
9 & Desa SumberBendo & 0,5 & $\mathbf{8 5 3}$ & $\mathbf{5 6 0}$ \\
10 & Desa Sambirejo & $\mathbf{9}$ & & \\
& Total & & & \\
\hline
\end{tabular}

Tahapan budi daya ikan lele meliputi proses: pemijahan, penetasan telur lele, grading bibit, proses pembesaran, dan proses pemanenan. Pembesaran lele dilakukan selama 100 hari pada kolam terpal oleh 17 karyawan dan kolam permanen oleh 12 
karyawan. Kepadatan tebar adalah : kolam permanen 500 ekor bibit $/ \mathrm{m}^{2}$, kolam terpal 450 ekor bibit $/ \mathrm{m}^{2}$. Pada penelitian ini, analisis keuangan yang dilakukan lebih berfokus pada proses pembesaran ikan lele pada kolam terpal dan kolam permanen.

\section{Biaya Operasional}

Proses budi daya ikan lele memerlukan biaya operasional yang digunakan untuk membiayai proses budidaya tersebut, biaya operasional yaitu terdiri dari biaya variable dan biaya tetap. Komponen biaya yang termasuk pada biaya tetap adalah biaya penyusutan, angsuran kredit beserta bunga bank dan komponen biaya variable yang dimaksud adalah biaya pembelian bibit, pakan, tenaga kerja, pajak, dan listrik. Biaya operasional rata-rata usaha budi daya ikan lele kolam permanen dan terpal per hektar secara berturut-turut adalah $\mathrm{Rp}$ 22.450.182.619/ tahun dengan rincian biaya variable $\mathrm{Rp}$. 19.351.864.841/ tahun dan biaya tetap sebesar Rp 3.098.317.778/tahun, Rp 13.871.657.130/ tahun dengan rincian biaya variable Rp. 11.166.343.797/tahun dan biaya tetap sebesar $\operatorname{Rp}$ 2.705.313.333/tahun. Rincian dari komponen biaya operasional dapat dilihat pada Tabel 3.

Tabel 3. Rincian biaya operasional budi daya ikan lele per hektar

\begin{tabular}{|c|c|c|c|c|c|}
\hline No & Uraian & $\mathrm{Jml}$ & Biaya/tahun(Juta Rp) & $\mathrm{Jml}$ & Biaya/tahun(Juta Rp) \\
\hline \multirow{2}{*}{\multicolumn{6}{|c|}{ Biaya Variabel }} \\
\hline & & & & & \\
\hline 1 & Bibit Ikan & & 2.706.666.667 & & 1.669 .747 .500 \\
\hline 2 & Pakan Ikan & & 14.168 .000 .000 & & 8.757 .466 .667 \\
\hline 4 & Tenaga Kerja & & 72.000 .000 & & 51.000 .000 \\
\hline 5 & Listrik & & 13.440 .000 & & 10.236 .000 \\
\hline & Biaya Tetap & & & & \\
\hline 1 & Biaya & & 167.651 .111 & & 507.313 .333 \\
\hline 2 & $\begin{array}{l}\text { Penyusutan } \\
\text { Tenaga Keria }\end{array}$ & & 8.750 .000 & & 8.750 .000 \\
\hline 3 & $\begin{array}{l}\text { Tenaga Kerja } \\
\text { Biaya Abonemen }\end{array}$ & & 180.000 & & 180.000 \\
\hline 4 & Angsuran Pokok & & 2.666.666.667 & & 2.000 .000 .000 \\
\hline 5 & Bunga Kredit & & 264.000 .000 & & 198.000 .000 \\
\hline & TOTAL & & Rp20.067.354.445 & & Rp13.202.693.500 \\
\hline
\end{tabular}

\section{Proyeksi Laba-rugi}

Proyeksi laba-rugi mengilustrasikan pendapatan dan pengeluaran sebuah usaha setiap periode. Laba kotor merupakan selisih dari total pendapatan dengan total biaya operasional, sedangkan laba bersih adalah selisih laba kotor dengan bunga pinjaman (kredit investasi modal tetap dan modal kerja) dan pajak dari pendapatan kena pajak. Rincian laba-rugi dapat dilihat pada Tabel 4.

\section{Proyeksi Aliran Kas}

Proyeksi aliran kas menggambarkan penerimaan dan pengeluaran yang berlangsung selama periode kajian akuntansi tertentu. Aliran kas masuk dalam usaha budi daya lele terdiri dari kredit investasi, bunga masa usaha , total pendapatan. Sebaliknya, aliran kas keluar terjadi dari pembiayaan investasi, biaya tetap, biaya variabel, pengembalian pinjaman dan pajak pendapatan. Aliran kas bersih pada suatu periode adalah selisih dari total aliran kas masuk dengan total aliran kas keluar pada periode yang bersangkutan. Berdasarkan dari hasil perhitungan maka total aliran kas masuk tahun pertama hingga tahun kelima kolam permanen dan kolam terpal per hektar 
berturut-turut adalah Rp 22.294.878.388 dan Rp 13.452.807.453, total aliran kas keluar pada tahun ke-0 adalah $\mathrm{Rp}$ 13.333.333.333 dan Rp 10.000.000.000 maka usaha budi daya layak untuk dilakukan. Perincian aliran kas bersih masuk dapat dilihat pada Tabel 5.

Tabel 4. Analisis Laba Rugi Usaha Budi Daya Ikan Lele

\begin{tabular}{|c|c|c|}
\hline Uraian Laba Rugi & Kolam Permanen/Ha & Kolam Terpal/Ha \\
\hline Pendapatan & Rp $\quad 26.898 .995 .200$ & $\operatorname{Rp} 16,651,791,732$ \\
\hline Biaya Variable & 14.051 .711 .860 & $\operatorname{Rp} 10,565,516,881$ \\
\hline Penyusutan & 154.184 .444 & $\mathrm{Rp} \quad 448,713,333$ \\
\hline Laba Kotor & 12.847 .283 .340 & $\operatorname{Rp} \quad 6,086,274,851$ \\
\hline Angsuran Per tahun & 2.666.666.667 & $\operatorname{Rp} 2,000,000,000$ \\
\hline Bunga Kredit & 264.000 .000 & $\mathrm{Rp} \quad 198,000,000$ \\
\hline Laba Kena Pajak & 9.762 .432 .229 & $\operatorname{Rp} 3,439,561,518$ \\
\hline Pajak $(25 \%)$ & 2.395.061.745 & Rp $\quad 826,066,741$ \\
\hline Laba Bersih & 7.367.370.484 & Rp $2,613,494,777$ \\
\hline Profit Margin & $27 \%$ & $16 \%$ \\
\hline
\end{tabular}

Tabel 5. Aliran kas bersih Kolam Permanen dan Terpal

\begin{tabular}{crr}
\hline Aliran Kas Tahun Ke- & Kolam Permanen/Ha & Kolam Terpal/Ha \\
\hline 0 & $(13.333 .333 .333)$ & $(10.000 .000 .000)$ \\
1 & 3.980 .011 .084 & 2.776 .500 .793 \\
2 & 9.590 .339 .191 & 5.036 .218 .863 \\
3 & 13.968 .825 .789 & 7.746 .33 .812 \\
4 & 18.246 .385 .580 & 10.411 .060 .859 \\
5 & 22.294 .878 .388 & 13.452 .807 .453 \\
Total & 22.294 .878 .388 & 13.452 .807 .453 \\
\hline
\end{tabular}

\section{Analisis Kelayakan Finansial}

Tingkat kelayakan finansial usaha budi daya kolam permanen dan kolam terpal per hektar pada tingkat suku bunga bank 9,9\% (berdasarkan hasil wawancara langsung kepada pegawai bank BCA dan bank Mandiri) secara berturut-turut. Berdasarkan hasil perhitungan yang dilakukan diperoleh nilai NPV Rp 6.019.446.814 dan Rp 1.610.582.269 sehingga secara finansial usaha budi daya ikan lele memiliki kemampuan untuk melanjutkan investasi tersebut karena usaha tersebut memiliki nilai NPV $(>0)$. Hasil perhitungan IRR proyek adalah $21.05 \%$ dan $10.58 \%$ berarti usaha layak dilaksanakan dan akan menguntungkan karena nilainya lebih besar dari rata-rata tingkat suku bunga deposito bank yaitu sebesar 5,36\%. Berdasarkan perhitungan usaha budi daya lele yang memberikan nilai Net B/C 1,20 dan 1.19 (lebih besar dari satu). Hasil perhitungan BEP Rp 11.070.976.335 dan Rp 8.296.228.975 hal ini menunjukkan bahwa selama umur ekonomis usaha budi daya, nilai dan kapasitas produksi berada di atas nilai dan kapasitas titik impas. Hasil perhitungan waktu pengembalian modal proyek industri lele yang adalah 2,99 atau 3 tahun dan 3,71 atau sekitar 3 tahun 9 bulan. Rincian kelayakan finansial dapat dilihat pada Tabel 6. 
Tabel 6. Kelayakan Finansial Kolam Permanen dan Kolam Terpal

\begin{tabular}{|c|c|c|}
\hline Kelayakan Finansial & Kolam Permanen/Ha & Kolam Terpal/Ha \\
\hline NPV & $\begin{array}{ll}\mathrm{Rp} & 6.019 .446 .814\end{array}$ & Rp 1.610.582.269 \\
\hline IRR & $21.05 \%$ & $10.58 \%$ \\
\hline Net B/C & 1,20 & 1,19 \\
\hline BEP & Rp 11.070.976.335 & Rp 8.296.228.975 \\
\hline PBP & 2,99 & 3,72 \\
\hline Kesimpulan & Layak & Layak \\
\hline
\end{tabular}

\section{KESIMPULAN DAN SARAN}

\section{Kesimpulan}

Berdasarkan penelitian yang telah dilakukan maka dapat disimpulkan beberapa hal sebagai berikut :

1. Tahapan budi daya ikan lele meliputi proses: pemijahan, penetasan telur lele, grading bibit, proses pembesaran, dan proses panen. Pembesaran lele dilakukan selama 100 hari. Kepadatan tebar adalah : kolam permanen 500 ekor bibit $/ \mathrm{m}^{2}$, kolam terpal 450 ekor bibit $/ \mathrm{m}^{2}$. Dengan tingkat kematian pada kolam permanen sebesar $8,236 \%$ dan kolam terpal $9,131 \%$.

2. Modal investasi kolam permanen $\mathrm{Rp}$ 2.514.766.667/Ha. Pendapatan rata - rata selama lima tahun (2013-2017) kolam permanen adalah Rp 23.918.347 /siklus/kolam, maka pendapatan per tahun adalah Rp 86.106.049 /kolam/tahun. Untuk kolam terpal Rp 1.642.425.000/Ha. Pendapatan rata - rata adalah $\mathrm{Rp}$ 19.005.054/kolam/siklus maka pendapatan per tahun adalah Rp 68.418.193 /kolam/tahun. Tingkat kelayakan finansial untuk kolam permanen dan terpal/Ha pada (suku bunga bank 9,9\%) secara berturut-turut : NPV Rp 5.975.446.295 dan Rp 1.645.894.923 (> 0 ); IRR $17,62 \%$ dan $10,57 \%$; Net B/C ratio 1,20 dan 1.19 (>1). Mencapai titik impas (BEP) pada saat produksi 0,201 dan 0,149/tahun nilai $\mathrm{Rp} 11.082 .314 .678$ dan Rp 8.238.792.702/tahun, dan (PBP) tercapai pada saat 3,00 atau 3 tahun dan 3,71 atau 3 tahun 9 bulan. Seluruh kriteria analisis finansial ini menunjukkan bahwa usaha budi daya ikan lele adalah layak.

\section{Saran}

Berdasarkan hasil penelitian ini dapat disarankan beberapa hal sebagai berikut :

1. Usaha budi daya ikan lele secara finansial, sangat menjanjikan dan patut dikembangkan di wilayah lainnya di Indonesia sehingga dapat membuka lapangan pekerjaan baru.

2. Berdasarkan hasil penelitian maka apabila ingin memulai budi daya ikan lele maka lebih di sarankan untuk melakukan investasi pada kolam permanen karena secara finansial dapat menghasilkan keuntungan lebih besar dan tingkat kematian ikan yang lebih rendah.

\section{DAFTAR PUSTAKA}

Andrianto, I.T.T., 2005. Pedoman Praktis Budidaya Ikan Lele. Absolut. Yogyakarta.

Bidayani, E. 2007. Analisis Usaha Budidaya Ikan Patin (Pangasius pangasius) dan Lele Dumbo (Clarias gariepinus) Hasil Substitusi Pelet dengan Usus Ayam di Kolong Bekas Penambangan Timah Aquatik jurnal sumber daya perairan volume 1. Edisi 1 ISSN 1978 165221.

Choliq, A., R. Wirasasmita dan O. Sofwan, 1994. Evaluasi Proyek (Suatu Pengantar).Pionir Jaya, Bandung. 
Dewi, N. P. H., I. K. Satriawan., dan L. P. Wrasiati. 2017. Analisis Nilai Tambah Pengolahan dan Kelayakan Finansial Minuman Bubuk Herbal Bawang Berlian. Jurnal Rekayasa dan Agroindustri. 5(2) : 67-76.

Dianti, I., Sobari, M.P. dan Irianni, R. 2007. Analisis Kelayakan Finansial Ikan Nila Wanayasa Pada Kelompok Pembudi Daya Mekarsasi. Jurnal Akuakultur Indonesia. 6 (1): 97 - 102.

Direktorat Jendral Perikanan Budidaya. 2015. Statistik Perikanan Budidaya Indonesia Tahun 2010 - 2015, Direktorat Jendral Perikanan Budidaya, Jakarta.

Gray, C., P. Simanjuntak, L. K. Sabur, P.F.L. Maspaitella dan R.C.G. Varley. 1992.Pengantar Evaluasi Edisi Kedua. PT. Gramedia Pustaka Utama, Jakarta.

Husan, S. dan Suwarsono. 1997. Studi Kelayakan Proyek Edisi Ketiga. UPP AMP YKPN, Yogyakarta.

Ibrahin, J. 2003. Studi Kelayakan Bisnis. Edisi Revisi Cetakan Kedua. Penerbit PT.Renika Cipta. Jakarta.

Kadariah., Karlina L., dan Gray C, 1999. Pengantar Evaluasi Proyek. Edisi Revisi. Jakarta : Lembaga Penerbit Fakultas Ekonomi Universitas Indonesia, Jakarta.

Kasmir dan Jakfar. 2007 Studi Kelayakan Bisnis, Jakarta. Edisi Kedua. Cetakaan Keempat. Penerbit Prenada Media Group.
Kusuma, P. T. W. W., Hidayat, D.D dan Indrianti, N. 2012. Analisis Kelayakan Finansial Pengembangan Usaha Kecil Menengah (UKM) nata de coco di sumedang, Jawa Barat. Jurnal Teknotan. $6: 607-676$.

Malulidah. S dan D.E.Pratiwi. 2010. Finansial Feasibility Analysis of Prabu Bestari Grapes Parming. JurnalAGRISE. 9(3) : 1412-1925

Novia, W., W. A. Zakaria., dan D.A.H. lestari. 2013. Analisis Nilai Tambah dan Kelayakan Pengembangan Agroindustri Beras Siger. JIIA. 1 (3): $210-217$.

Peraturan Menteri Keuangan No. 141/PMK.03/2016.

Setiawan, B. B. 2006. Budidaya Ikan Lele. Penerbit Pustaka Indonesia. Cetakan Pertama. Bandung.

Soekartawi, 1991. Dasar Penyusunan Evaluasi Proyek. Pustaka Sinar Harapan. Jakarta.

Tiyas, A., I. G. S. A. Putra., dan I. A. L. Dewi. 2015. Analisis Finansial Usahatani Buah Naga Super Merah (Hylocereus costaricensis) (Studi Kasus di kelompok Tani Berkah Naga Desa Sambirejo Kecamatan Bangorejo Kabupaten Banyuwangi. E-jurnal Agribisnis dan Agrowisata. 4(5):23016523 